\title{
Incidence of Bloodstream Infection Among Patients on Hemodialysis by central Venous Catheter
}

\author{
Cibele Grothe ${ }^{1}$ \\ Angélica Gonçalves da Silva Belasco² \\ Ana Rita de Cássia Bittencourt ${ }^{3}$ \\ Lucila Amaral Carneiro Vianna ${ }^{4}$ \\ Ricardo de Castro Cintra Sesso 5 \\ Dulce Aparecida Barbosa ${ }^{6}$
}

\begin{abstract}
This study evaluated the incidence and risk factors of bloodstream infection (BSI) among patients with a double-lumen central venous catheter (CVC) for hemodialysis (HD) and identified the microorganisms isolated from the bloodstream. A follow-up included all patients $(n=156)$ who underwent hemodialysis by double-lumen CVC at the Federal University of São Paulo - UNIFESP, Brazil, over a one-year period. From the group of patients, 94 presented BSI, of whom 39 had positive cultures at the central venous catheter insertion location. Of the 128 microorganisms isolated from the bloodstream, 53 were S. aureus, 30 were methicillin-sensitive and 23 were methicillin-resistant. Complications related to BSI included 35 cases of septicemia and 27 cases of endocarditis, of which 15 cases progressed to death. The incidence of BSI among these patients was shown to be very high, and this BSI progressed rapidly to the condition of severe infection with a high mortality rate.
\end{abstract}

Descriptors: Catheterization; Renal Dialysis; Staphylococcus aureus.

Departamento de Enfermagem, Universidade Federal de São Paulo, Brazil:

${ }^{1}$ Doctoral Student in Health Sciences, e-mail: cibelegrothe@hotmail.com.br.

${ }^{2}$ Post-doctoral degree in Sciences Nephrology, Adjunct Professor, e-mail: abelasco@denf.epm.br.

${ }^{3}$ Ph.D. in Health Sciences, Adjunct Professor, e-mail: anarita@denf.epm.br.

${ }^{4}$ Ph.D. in Health Sciences, Full Professor, e-mail: Ivianna@reitoria.epm.br.

${ }^{5}$ Ph.D. in Medicine, Adjunct Professor, e-mail:rsesso@nefro.epm.br.

${ }^{6}$ Post-doctoral degree in Sciences Nephrology, Adjunct Professor, e-mail: dulce@denf.epm.br.

Corresponding Author:

Cibele Grothe

Secretaria de Pós Graduação. Departamento de Enfermagem. Universidade

Federal de São Paulo

Rua Napoleão de Barros, 754

Vila Clementino

CEP: 04024-002 São Paulo, SP, Brasil

E-mail: cibelegrothe@hotmail.com.br 


\title{
Incidência de infecção da corrente sanguínea nos pacientes submetidos à hemodiálise por cateter venoso central
}

O objetivo deste estudo foi avaliar a incidência e os fatores de risco de infecção da corrente sanguínea (ICS) em pacientes com cateter venoso central (CVC) duplo lúmen, para hemodiálise (HD) e identificar os micro-organismos isolados na corrente sanguínea. Como método, usou-se o follow up, realizado no período de um ano, incluindo todos os 156 pacientes que estavam em tratamento de HD por CVC duplo lúmen, na Universidade Federal de São Paulo - UNIFESP. Os resultados mostraram que dos 156 pacientes estudados, 94 apresentaram ICS, desses, 39 tiveram culturas positivas no local de inserção do cateter. Dos 128 micro-organismos isolados da corrente sanguínea, 53 eram S.aureus, dos quais 30 eram sensíveis à metilcilina e 23 resistentes. Entre as complicações relacionadas à ICS, houve 35 casos de septicemia e 27 casos de endocardite, dos quais 15 progrediram a óbito. A incidência de ICS neste grupo de pacientes mostrou-se bastante elevada bem como sua progressão para quadros infecciosos de grande magnitude e óbito.

Descritores: Cateterismo; Diálise Renal; Staphylococcus aureus.

\section{Incidencia de infección de la corriente sanguínea em los pacientes sometidos a hemodiálisis por catéter venoso central}

\begin{abstract}
El objetivo de este estudio fue evaluar la incidencia y los factores de riesgo de infección de la corriente sanguínea (ICS) en pacientes con catéter venoso central (CVC) doble lumen, para hemodiálisis (HD) e identificar los microorganismos aislados en la corriente sanguínea. Como método, se uso el acompañamiento, realizado en el período de un año, incluyendo todos los 156 pacientes que estaban en tratamiento de HD por CVC doble lumen, en la Universidad Federal de Sao Paulo - UNIFESP. Los resultados mostraron que de los 156 pacientes estudiados, 94 presentaron ICS, de estos, 39 tuvieron culturas positivas en el local de inserción del catéter. De los 128 microorganismos aislados de la corriente sanguínea, 53 eran S.aureus, de los cuales 30 eran sensibles a la metilcilina y 23 resistentes. Entre las complicaciones relacionadas a la ICS, hubo 35 casos de septicemia y 27 casos de endocarditis, de los cuales 15 resultaron en muerte. La incidencia de ICS en este grupo de pacientes se mostró bastante elevada así como su progresión para cuadros infecciosos de gran magnitud y de muerte.
\end{abstract}

Descriptores: Cateterismo; Diálisis Renal; Staphylococcus aureus.

\section{Introduction}

Central venous catheters (CVC) are a reliable option for clinical situations requiring immediate vascular access for hemodialysis, as in the case of patients with uremia(1). $^{(1)}$

A variety of mechanisms have been proposed to determine the sources of microorganisms that colonize CVCs and lead to infections. Studies have focused mainly on: the patient's skin around the exit site and to a lesser extent contamination of the catheter connection; colonization of the catheter by hematogenic dissemination coming from another site; and/or contamination of the infusion fluid. Other possibilities are the occurrence of catheter contamination at the time of insertion as a result of a lack of aseptic technique or through iatrogenic contamination during subsequent manipulations of the catheter. This last category of possible catheter contaminations may originate from the hands and/or respiratory tracts of health care providers ${ }^{(2)}$. Moreover, patients on dialysis are known to suffer from impaired immune defense mechanisms, attributable to the larger proportions of elderly polymorbid patients with conditions such as diabetes mellitus and malignancies, 
in addition to malnutrition, particularly related to uremia and HD treatment ${ }^{(3)}$.

Among the microorganisms responsible for Bloodstream Infection (BSI) in hemodialysis patients, S. aureus is the most important. Data in the literature have shown high morbidity and mortality rates among patients who develop BSI related to the use of CVCs for hemodialysis(4-5). Consequently, there is a rise in both hospital costs and microbial resistance ${ }^{(1,6)}$. Therefore, the prevention of such BSI needs to be considered a priority matter in programs for infection control and hospital quality control assessment.

There were no data about the incidence of hospital infections in the nephrology service at the UNIFESPBrazil. Therefore, the present study was designed to evaluate the prevalence of risk factors for BSI among patients with double-lumen CVC for hemodialysis, and to identify the microorganisms isolated from the bloodstream of patients. It was assumed that results of this study would bring important clinical contributions for preventing this major infectious complication in patients on hemodialysis by double-lumen CVC in the institution.

\section{Objective}

- To evaluate the incidence and the risk factors of BSI among patients with a double-lumen central venous catheter for hemodialysis;

- To identify the microorganisms isolated from the blood stream in these patients.

\section{Methods}

The study was approved by the institutional review board, and informed consent was obtained from all participants.

\section{Design, location, and period of the study}

A follow up was conducted at the Federal University of São Paulo, a tertiary referral center in São Paulo, Brazil, with a dialysis unit that serves 40 to 50 patients weekly.

\section{Patients}

The study included 156 new end-stage renal disease (ESRD) patients without permanent venous access and urgently in need of hemodialysis. Patients were excluded if they had acute renal failure or presented septicemia or another source of infection.

All venous catheters (Mahurkar ${ }^{\circledR}$ dual lumen catheters, Quinton Instrument Co., Bothell, WA) were inserted aseptically by nephrology staff physicians, either in the internal jugular or subclavian veins using the Seldinger technique. All catheters were sutured in place without a subcutaneous tunnel or adhesive transparent dressing. After initial insertion of the catheters, only nephrology nurses trained in hemodialysis changed the dressings or manipulated the catheters, using rigorous aseptic techniques. The catheters were locked with 2500 to 3000 IU of heparin sodium both at the time of insertion and after each dialysis.

The patients selected for the study were assigned to receive skin disinfection at the catheter insertion site with $70 \% \mathrm{P} / \mathrm{V}$ alcohol solution. The exit site, catheter hub, and line connections were covered with sterile, occlusive gauze dressing.

At the time of inclusion in the study, demographic and clinical data were recorded.

\section{Follow- up}

The catheters' dressings were removed before each dialysis. A nurse assessed the exit site for inflammation or the presence of pus at the dressing change and when the catheter was removed. Participants were followed up with until the catheter was removed, which occurred for the following reasons: catheter malfunction, the presence of local erythema and/or a purulent discharge, or BSI without another identifiable source of infection, accordingly to Kidney Disease Outcomes Quality Initiative (KDOQI) recommendations. If local erythema alone was present, the catheter was left in situ, provided there was no evidence of BSI. No patient was lost to follow-up, and no catheter was exchanged over a guidewire. No patient used more than one catheter during the study period. Catheters were only used for hemodialysis.

Immediately before catheter removal, the skin around the site was cultured with a saline-moistened cotton swab and then cleaned with povidone iodine. Exit site cultures were also obtained when there was a clinical suspicion of skin infection. If a patient presented a fever $\left(37.8^{\circ} \mathrm{C}\right)$, with or without other signs of infection, blood cultures were collected from peripheral veins, using 
standard aseptic techniques. All catheters were removed in the dialysis unit of São Paulo Hospital.

Definition of terms

Skin Infections: Presence of one or more of the following signs or symptoms with no other recognized cause: pain or tenderness, localized swelling, redness, or heat and the growth of microorganisms in skin cultures $^{(7-8)}$

Colonization of the Catheter Tip: Semiquantitative culturing of catheter tips containing 15 or more colonyforming units (cfu) per dish(7-8).

Bloodstream infection: Acknowledged according to the following criteria: 1) presence of one or more positive blood cultures (collected from peripheral veins) while the catheter was in place; 2 ) presence of fever greater than $37.8^{\circ} \mathrm{C}$ accompanied by chills, or hypotension; 3 ) evaluation of data from clinical examination, chest $x$-ray, and laboratory and microbiological investigation that do not suggest another source for the bacteremia; and 4 ) presence or absence of positive culture from the catheter $\operatorname{tip}^{(7-8)}$.

\section{Microbiology}

Pericatheter skin samples were obtained using sterile, pre-moistened calcium alginate swabs (Cefar-Farmaco Diagnostic, São Paulo, Brazil) and were transported to the microbiology laboratory of São Paulo Hospital, where they were immediately streaked onto plates containing tryptic soy agar with $5 \%$ sheep blood and mannitol-salt agar (DIFCO Laboratories, Detroit, MI). All cultures were incubated at $35^{\circ} \mathrm{C}$ for 48 hours and examined daily for evidence of growth. Gram-positive cocci that produced catalase and coagulase were identified as S. aureus. Methilcillin- resistant S.aureus strains were defined as a zone of inhibition less than $11 \mathrm{~mm}$ (disk content of methilcillin was $1 \mu \mathrm{g}$ ). Blood samples (20ml) were collected in Bactec bottles, and cultures were processed by an automated method of isolation for microorganisms (Bactec 9240, Becton Dickinson).

After the catheter was removed, approximately 50 $\mathrm{mm}$ of the catheter tip was rolled across Rodac plates containing tryptic soy agar with $5 \%$ sheep blood (AS, Oxoid, Basingstoke, Hampshire, United Kingdom), and mannitol-salt agar (ASM, Oxoid), prepared previously in the laboratory, according to the semi-quantitative method. Catheters yielding more than 15 colony-forming units were considered significantly colonized ${ }^{(7)}$.

\section{Statistical analysis}

Patients were classified into 2 groups: with and without BSI. Descriptive analysis of each of these 2 groups was performed considering demographic, clinical and laboratory variables and parameters relating to dialysis. After this, univariate analysis was performed. Associations between BSI and categorical variables were tested by using chi-square and Fisher's exact tests. Associations between continuous variables and BSI were tested by using Student's $t$ - test or the MannWhitney test, as appropriate. Multivariate analysis was also performed by means of stepwise logistic regression to investigate factors associated with BSI. Independent variables tested were those that presented $P$ less than 0.01 in univariate analysis. Relative risk (RR) and 95\% confidence intervals (CIs) were calculated. The tests used were bimodal and the significance level was set at $p$ less than 0.05. Microbiological analyses were performed in accordance with the norms of the National Committee for Clinical Laboratory Standards (NCCLS). The statistical program used was SPSS (version 14.0).

\section{Results}

Of the 156 patients that entered the study; 94 developed BSI. All patients were followed until catheter removal. Table 1 shows the baseline characteristics: sociodemographic, clinical data and treatment of the patients who underwent hemodialysis via CVC in the study.

In relation to base diseases, patients with hypertension and diabetes mellitus presented an increased risk of developing BSI, 22\% (RR: 1,22; 95\% confidence interval: $0.86-3.14$ ) and 37\% (RR: 1.37; 95\% confidence interval: $1.16-5.26)$ respectively.

As for the CVC insertion site, there were more catheters implanted in a subclavian vein $(n=92)$, compared to the jugular vein $(n=64)$, where patients who had double-lumen CVC implanted in the jugular vein were $56 \%$ more likely (RR: $1.56 ; 95 \%$ confidence interval: 1.50 - 5.65) to develop BSI than those who had the catheter implanted in a subclavian vein.

The duration of catheterization and length of hospitalization were significantly higher $(p=0.04$ and $p$ $<0.001$ ) among patients who had BSI (Table 1 ). 
Table 1 - Sociodemographic Characteristics, Clinical Data and Treatment for the Patients who Underwent Hemodialysis by Double-lumen CVC and Evolved with and without BSI

\begin{tabular}{|c|c|c|c|}
\hline \multirow{2}{*}{ Characteristics } & Positive for BSI $(n=94)$ & Negative for BSI $(n=62)$ & \multirow{2}{*}{$\begin{array}{l}\text { Relative risk (95\%) } \\
\text { confidence interval) }\end{array}$} \\
\hline & n (\%) & n (\%) & \\
\hline \multicolumn{4}{|l|}{ Sex } \\
\hline Male & $49(59.8 \%)$ & $33(40.2 \%)$ & $0.98(0.50-1.81)$ \\
\hline Female & $45(60.8 \%)$ & $29(39.2 \%)$ & $1.01(0.55-1.98)$ \\
\hline Average age (with range) & $51(14-94)$ & $53(17-78)$ & $0.59(0.08-0.45)$ \\
\hline \multicolumn{4}{|l|}{ Race } \\
\hline White & $54(62.4 \%)$ & $31(37.6 \%)$ & $1.12(0.70-2.57)$ \\
\hline Non-white & $40(57.7 \%)$ & $31(42.3 \%)$ & $0.88(0.38-1.41)$ \\
\hline \multicolumn{4}{|l|}{ Underlying disease* } \\
\hline Hypertensive disease & $57(65.5 \%)$ & $30(34.5 \%)$ & $1.22(0.86-3.14)$ \\
\hline Diabetes mellitus & $35(74.5 \%)$ & $12(25.5 \%)$ & $1.37(1.16-5.26)$ \\
\hline Autoimmune disease & $16(55.2 \%)$ & $13(44.8 \%)$ & $0.89(0.34-1.74)$ \\
\hline Cardiopathy & $16(64.0 \%)$ & $9(36.0 \%)$ & 1.07 (0.49- 2.93) \\
\hline Neoplastic disease & $4(57.1 \%)$ & $3(42.9 \%)$ & $0.94(0.18-4.04)$ \\
\hline \multicolumn{4}{|l|}{ Implantation location } \\
\hline Jugular vein & $65(69.0 \%)$ & $27(43.5 \%)$ & $1.56(1.50-5.65)$ \\
\hline Subclavian vein** & $29(31.0 \%)$ & $35(56.5 \%)$ & $0.64(0.17-0.66)$ \\
\hline Average duration of catheterization (days) (with range) $)^{\star *}$ & $19(2-90)$ & $13(2-23)$ & $0.98(0.43-2.10)$ \\
\hline Average length of hospitalization (days) (with range) ${ }^{* *}$ & $29(5-120)$ & $12(2-38)$ & $1.25(0.86-4.00)$ \\
\hline
\end{tabular}

Note: values are presented as number of patients $(n)$ and percentage $(\%)$, or as average and range; $*$ Some patients presented more than one underlying disease; $* * p<0.001$

The complications related to the use of the doublelumen CVC that affected the patients undergoing hemodialysis and developed BSI are presented in Table 2. The patients with positive cultures from the catheter tip presented a relative risk of developing BSI three times higher compared to the patients with positive cultures from local skin infections (RR: 3.01; 95\% confidence interval: $1.33-6.81$ ). Patients with positive exit site cultures had a 1.3 times greater chance of developing BSI, compared to patients with negative exit site cultures.

Patients who presented BSI had a 50\% higher risk of death compared to the group without BSI (Table 2).

Table 2 - Complications related to the use of the doublelumen CVC with and without BSI

\begin{tabular}{lccc}
\hline \multirow{2}{*}{ Complications } & $\begin{array}{c}\text { Positive for } \\
\text { BSI (n= 94) }\end{array}$ & $\begin{array}{c}\text { Negative for } \\
\text { without BSI } \\
(\mathbf{n}=\mathbf{6 2})\end{array}$ & $\begin{array}{c}\text { Relative risk (95\% } \\
\text { confidence interval) }\end{array}$ \\
\cline { 2 - 3 } & $\mathbf{n ~ ( \% )}$ & $\mathbf{n ~ ( \% )}$ & \\
\hline Skin infection & $39(41.5 \%)$ & $20(32.2 \%)$ & $1.29(0.83-1.98)$ \\
Catheter tip & $34(36.1 \%)$ & $6(9.8 \%)$ & $3.01(1.33-6.81)$ \\
infection** & & & \\
Endocarditis* & $27(28.7 \%)$ & -- & \\
Septicemia & $35(37.2 \%)$ & -- & \\
Death** & $27(28.7 \%)$ & $6(9.8 \%)$ & $1.50(1.19-1.88)$ \\
\hline
\end{tabular}

Values are presented as number of patients $(n)$ and percentage (\%)

* Out of the 27 deaths, 15 had endocarditis diagnosis

** $\mathrm{p}<0.001$.
Table 3 shows more detailed results of all microorganisms isolated from the bloodstream collected from patients with BSI. In 128 microorganisms isolated from the bloodstream $49 \%$ were Gram-positive, of which $56.6 \%$ were methicillin-sensitive staphylococcus aureus and $43.4 \%$ were methicillin-resistant S.aureus.

Table 3 - Microorganisms ( $n=128$ ) isolated from the blood cultures and causing BSI

\begin{tabular}{cc}
\hline Microorganisms & Positive for BSI $(\mathbf{n}=\mathbf{9 4})$ \\
\hline Gram-positive & $62(48.4 \%)$ \\
MSSA & $30(56.6 \%)$ \\
MRSA & $23(43.4 \%)$ \\
Gram-negative & $58(45.3 \%)$ \\
Gram-negative S* & $33(56.9 \%)$ \\
Gram-negative MR** & $25(43.1 \%)$ \\
Fungi & $8(6.2 \%)$ \\
\hline
\end{tabular}

* sensitive

** multiresistant

$\mathrm{n}=$ patients number

\section{Discussion}

The incidence of end-stage renal disease (ESRD) has risen dramatically over the last decade. In the United States alone, of 336.000 patients on dialysis (2004), 315.000 were undergoing hemodialysis, and the incidence has been increasing at the rate of $6 \%$ per year. The mean age of HD patients is increasing over time; 
today $26 \%$ of the HD population in the US is made up of elderly patients ${ }^{(9)}$.

On the other hand, even though this incidence is growing alarmingly, the survival of these renal patients as a whole is improving. According to the United States Renal Data System (USRDS), the mortality rates in the patients on peritoneal dialysis with a transplant are falling, whereas in patients on hemodialysis, the rate continues to rise, with an increase of $10 \%$ from 2003 to 2004, when the mortality rates rose from 243 per 1000 patients/year to 267 per 1000 patients/year ${ }^{(9)}$.

Among the diverse factors identified by these authors as being responsible for the raised incidence of infection in patients undergoing hemodialysis are: associated uremia immunosuppression, lack of aseptic technique in the access and manipulation of the vascular access, age of the catheter, the number of HD sessions. Longterm catheter use and a large number of hemodialysis sessions have been described as leading factors related to infection in HD patients, associated with a high-risk of developing sepsis or colonization of the catheter ${ }^{(1)}$. The cumulative hazard of catheter-related bacteremia was significantly magnified 3 weeks after insertion(5). Moreover, a higher incidence of vascular access infection was related to longer periods of hospitalization ${ }^{(6,10)}$.

In an analytical epidemiological cohort study, conducted in 630 patients with CVC in seven intensive care units of the Federal District, Brazil, the catheterization time was statistically significant for the presence of infection $(p<0.001)$ and the time of hospitalization was 3.5 times higher in the group of patients who had blood infections related to the $\mathrm{CVC}^{(11)}$. These reported findings are in accordance with the results found in the present study, namely the duration of catheter use and length of hospitalization that were significantly higher $(p<0.001)$ among patients who developed BSI.

Bacteremia occurred most frequently in catheters that remained implanted for more than 10 days. The incidence of bacteremia has been found to be greater in hospitalized patients than in outpatients(12).

Many studies have confirmed the correlation between the microorganisms identified on the skin around the catheter and those isolated from the catheter tip ${ }^{(1,12)}$. CVC become colonized either through extraluminal (skin-related) or intraluminal (hub or perfusate related) routes. In the first case, organisms migrate from the exit site along the catheter and then reach the bloodstream. In the second, the catheter hubs are contaminated during catheter manipulation by dialysis personnel. Then, the colonizing bacteria spread into the lumen of the catheter ${ }^{(2)}$. For long-term catheters, particularly those cuffed and/or surgically implanted, the hub is a major source of colonization in catheters ${ }^{(1)}$.

In the present study, the relative risk of BSI was three times higher (RR: $3.01 ; 95 \%$ confidence interval: $1.33-6.81 ; \mathrm{p}<0.001$ ) in patients who had concomitantly present microorganisms in the tip of the catheter and in the bloodstream. Furthermore, patients with a positive skin culture around the catheter had a relative risk of developing BSI about 1.3 times higher (RR: 1.29; 95\% confidence interval: 0.83-1.98; $\mathrm{p}<0.001)$.

Studies found that the risk of infection increased significantly with insertion into the internal jugular vein (RR: $4.2 ; 95 \%$ confidence interval: 2.0-8.8) compared to insertion into a subclavian vein ${ }^{(1)}$. However, this risk always has to be weighed against non-infectious complications (pneumothorax, bleeding, and vein stenosis) associated with subclavian vein insertion ${ }^{(9)}$.

In this study, patients who had a central venous catheter implanted in the jugular vein presented a $56 \%$ higher (RR: 1.56 ; 95\% confidence interval: $1.50-5.65$ ) chance of developing BSI than did those who had the catheter implanted in a subclavian vein, in agreement with the current literature.

Bacterial infections in dialysis patients seem to progress rapidly, and recovery is slower than in nonuremic patients. This fact may be related to immunological alterations in patients with terminal chronic renal insufficiency, which include: deficient humoral immunity due to deficiencies in amino acids, vitamins B, C, D and $E$, and zinc; increased activity of suppressor cells, anorexia due to retention of nitrogenated products, and significant anemia secondary to erythropoietin deficiency. Accidental losses of iron during dialysis, and also diminished survival of erythrocytes in uremia, also increase the risk of infectious processes that are a predictive factor for mortality ${ }^{(4)}$.

Metastatic complications occur in a large proportion of chronic renal patients with bacteremia related to CVC; these complications include: endocarditis, osteomyelitis, septic arthritis, septic pulmonary emboli, and spinal epidural abscesses ${ }^{(13-14)}$.

In a study including 210 patients with ESRD who were undergoing chronic hemodialysis, 31\% developed complications due to $S$. aureus Bacteremia. Of these, endocarditis was present in $17.1 \%$, abscess in $5.7 \%$, sepsis in $4.8 \%$ and $3.4 \%$ other complications ${ }^{(11)}$. Infectious complications associated with temporary HD catheters represent one of the most important sources of morbidity and mortality among these patients(15-16). 
Septicemia accounts for almost $11 \%$ of mortalities among HD patients ${ }^{(16)}$. IE in HD patients has a poor prognosis, as illustrated by in-hospital and one-year death rates ranging from 25 to $45 \%$ and from 46 to $75 \%$ respectively ${ }^{(17)}$.

In 1999, for the first time since the National Nosocomial Infections Surveillance (NNIS) has been reporting susceptibilities, more than $50 \%$ of all $S$ aureus isolates from ICUs were resistant to Oxacillin ${ }^{(10)}$ and in 2003 this number increased by $60 \%$. S. aureus has a unique predilection to cause fatal infections among those who have CVCs ${ }^{(14)}$.

In the present study, among the 128 microorganisms isolated from blood cultures in the patients who presented BSI, 62 microorganisms were Gram-positive cocci, of which $56.6 \%$ were $M S S A$ and $43.4 \%$ were MRSA and 8 microorganisms were fungi. The high fungi and bacterial infection rates found in these patients can be related to their uremic immunosuppression ${ }^{(4)}$.

MRSA strains associated with the health system are generally not only resistant to beta-lactamic antibiotics, but also load diverse mutations and genes of resistance for, as an example, vancomycin, to which it remained sensitive for decades. Currently, strains not only resistant to vancomycin but also to teicoplamina have been isolated from the blood streams of hospitalized patients, leaving limited therapeutical options ${ }^{(10)}$.

Patients hospitalized with infection for S. aureus have 5 times higher risk of mortality ${ }^{(3)}$. Mortality associated with bacteremia caused by S.aureus varies from 11.9 to $46.5 \%$ per year ${ }^{(3)}$. During this study, there were 27 deaths that were caused by infectious complications related to central venous catheter BSI. The present study showed that the risk of death among patients who presented BSI was $50 \%$ higher than in patients without BSI.

This study data led to another article where the high lethality rate due to complications related to infective endocarditis $(56 \%)$ is analyzed. The most frequent cause of death was septicemia (54\%), and this was accompanied by cardiac insufficiency in 33\% of the cases and by embolism in $13 \%$ of the cases $^{(18)}$.

This study identified a high mortality rate in São Paulo Hospital dialysis patients and alerted us to the necessity to undertake new studies looking to minimize this alarming trend. Now that the causes of these BSIs have been related to catheter use, catheter infection prevention measures should be revised and reinforced with urgency. To avoid the spread of infection, rigorous measures must be utilized, ranging from washing hands to isolating patients with resistant strains and using individual personal protective equipment.

\section{Conclusion}

The incidence of BSI among patients who use a double-lumen CVC was very high (61\%). Likewise, progression of this BSI to conditions of severe infection occurred frequently. The risk factors for developing BSI in this study were: implantation of the catheter in the internal jugular vein, duration of catheter use, and length of hospitalization. The mortality rate was 29\% for patients who developed BSI and $55.5 \%$ of those who progressed to endocarditis. Among the microorganisms isolated, the ones most frequently found were Grampositive, of which $S$. aureus was the most prevalent; $56.6 \%$ was $M S S A$ and $43.4 \%$ was MRSA.

This study is in line with the current literature, complementing results of studies previously published in this journal, reinforcing that once hospitals learn which infections are most prominent in CVC related infections, efforts can be made to improve hospital infection control measures, including educating staff on proper techniques for the insertion and maintenance of CVCs, and instituting more efficient and effective quality control measures in hospital environments. These efforts and measures will contribute much to shortening hospital stays, decreasing mortality rates among hospitalized, hemodialysis patients, and providing better outcomes for those infected with S. aureus microorganisms.

\section{References}

1. Saxena AK, Panbotra BR. Haemodialysis catheter-reated bloodstream infections: Current treatment options and strategies for prevention. Swiss Med Wkly 2005; 135:127-38.

2. De Cicco M, Campisi C, Matovic M. Central venous catheter related bloodstream infections: Pathogenesis factors, new perspectives in prevention and early diagnosis. J Vasc Access 2003; 4:83-91.

3. Yoon HJ, Choi JY, Kim CO, Kim JM, Song YG. A comparison of clinical features and mortality among methicillin- resistant and methicillin-sensitive strains of Staphylococcus aureus Endocarditis. Yonsei Medical Journal 2005; 46(4):496-502.

4. Chand DH, Brier M, Strife CF. Comparison of vascular access type in pediatric hemodialysis patients with respect to urea clearance, anemia management, and serum albumin concentration. Am J Kidney Dis 2005; 45(2):303-8.

5. Naumovic RT, Jovanovic DB, Djukanovic LJ. Temporary 
vascular catheters for hemodialysis: a 3-year prospective study. Int J Artif Organs 2004; 27(10):848-54.

6. Gonçalves EA, Andreoli MC, Watanabe R, Freitas MC, Pedrosa $A C$, Manfred SR, et al. Effect of temporary catheter and later referral on hospitalization and mortality during the first year of hemodialysis treatment. Artf Organs 2004; 28(11):1043-9.

7. Centers for Disease Control and Prevention: Communityassociated methicillin-resistant Staphylococcus aureus infections in Pacific Islanders-Hawaii, 2001-2003. MMWR Morb Mortal Wkly Rep 2004; 53:767-70.

8. Horan. TC, Andrus. M, and Dudeck. MA. CDC/NHSN surveillance definition of health care-associated infection and criteria for specific types of infections in the acute care setting . Am J Infect Control 2008; 36:309-32.

9. United States Renal Data System [homepage on the Internet]. Bethesda: National Institutes of Health, National Institute of Diabetes and Digestive and Kidney Diseases; c2007 [updated 2007]. Annual Data Report: Atlas of Chronic Kidney Disease and End-Stage Renal Disease in the United States; [Chapter 2: ESRD incidence \& prevalence] Available from: http://www. usrds.org/2007/pdf/02_incid_prev_07.pdf

10. Engemann JJ, Friedman JY, Reed SD, Griffiths RI, Szczech LA, Kaye KS, et al. Clinical outcomes and costs due to Staphylococcus Aureus bacteremia among patients receiving long-term hemodialysis. Infect control hosp. Epidemiol 2005; 26(6):534-9.
11. Mesiano ERAB; Merchan-Hamann E. Bloodstream infections among patients using central venous catheters in intensive care units. Rev Latino-am Enfermagem 2007 June; 15(3):453-9.

12. Vanholder R. Central vein hemodialysis catheters and infection: a plea for timely referral and appropriate hygienic measures. Acta Clin Belg 2003 Nov-Dec; 58(6):342-4.

13. Jensen AG. Staphylococcus aureus bacteremia. Dan. Med. Bull 2003; 50(4):423-38.

14. Kim HS, Cho MS, Hwang SH, Ma SK, Kim SW, Kim NH, et al. Splenic abscess associated with endocarditis in a patient on hemodialysis: a case report. J Korean Med Sci 2005 Apr; 20(2):313-5.

15. Arduíno MJ, Tokars JI. Why is an infection control program needed in the hemodialysis setting? Nephrol News Issues 2005 Jun; 19(7):44-9.

16. Polkinghorne KR, McDonald SP, Atkins RC, Kerr PG. Vascular access and all-cause mortality: A propensity score analysis. J Am Soc Nephrol 2004; 15:477-86.

17. Doulton T, Sabharwal N, Cairns H S el ai. Infective endocarditis in dialysis patients: new challenges and old. Kidney/ nl 2003; 64:720-77.

18. Grothe C, Belasco A, Vianna L, Pignatari A, Sesso R, Barbosa D. Lethality of endocarditis due to $S$.aureus among patients on hemodialysis. Neprology Nursing Journal 2009 Sep-Out; 36(6): 613-9, 632.

Received: May. $5^{\text {th }} 2008$

Accepted: Sep. $2^{\text {nd }} 2009$ 